Jurnal MAKSIPRENEUR, Vol. III, No. 1, Hal 21-35

\title{
PERKEMBANGAN \\ KONSEP PEMASARAN: \\ IMPLEMENTASI \\ DAN IMPLIKASINYA
}

\section{Ambar Lukitaningsih (ambaryudono@yahoo.com)}

Fakultas Ekonomi Universitas Sarjanawiyata Tamansiswa

\begin{abstract}
Writing paper is conducted to reveal the development of the marketing concept, implementation and implications. The explanation begins with a description of the scope of marketing, a second discussion about the marketing concept and its development, followed by a discussion of the implementation of the marketing concept and concludes with managerial implications.
\end{abstract}

The development of the original understanding of marketing is more focused issue of physical distribution business enterprise then develop to the transaction which although not involve spending money and marketing activities can be carried out by institutions outside the business.

As a consequence of the expansion of the notion of marketing, the scope of marketing is also increasingly widespread. This process continues so that raises more and more marketing phenomenon. Phenomena are analyzed and presented by marketing experts, is then used as a reference in understanding the implementation of the marketing concept between the years 1960-1980's.

Changes have occurred with the theory of alternative marketing concept proposed by Fullerton (1988) and Houston (1986). In terms of the marketing concept, which originally seated over the company as the first and last of a series of business activities, changed completely to the consumer as the beginning and end of the company's activities. The development of the role of marketing revealed by Webster (1992) provides the latest alternative marketing concept that acts as an organizational network. Logical consequence all company activities should be directed to the consumer, given the conditions of competition has increased, but in doing its work, the company should be prosecuted execute better than its competitors in order eventually to provide customer satisfaction and this is the purpose of the company.

In order for consumer satisfaction can be integrated, then the company should use marketing as a strategic business concept that provides ongoing satisfaction, not a moment, not only for the investors / owners and consumers but also provide ongoing satisfaction also for its employees. In this concept the company seeks to satisfy all its stakeholders. 
But reality shows that although many businesses are aware of the importance of customer satisfaction, but still few of them are running customer service program is good and right. The program is limited to satisfying customers slogans and ceremonial. They are more likely to hunt for new customers and ignore existing customers. This phenomenon can be seen in the allocation of marketing costs are mostly devoted to the promotion and only a small portion devoted to retaining customers.

Keywords: Marketing Concepts, Implementation, Implications

\section{Pendahuluan}

Pemasaran merupakan sebuah faktor penting dalam siklus yang berhubungan dengan pemenuhan kebutuhan konsumen. Dalam perusahaan, pemasaran merupakan salah satu dari kegiatan pokok yang dilakukan perusahaan untuk mempertahankan kelangsungan hidupnya, berkembang dan mendapatkan laba, kegiatan pemasaran pada perusahaan juga harus dapat memberikan kepuasan pada konsumen jika menginginkan usahanya tetap berjalan.

Sejak orang mengenal kegiatan pemasaran, telah banyak ahli mengemukakan definisi tentang pemasaran yang kelihatannya sedikit berbeda tetapi memiliki arti yang sama. Perbedaan ini disebabkan karena mereka meninjau pemasaran dari sudut pandang yang berbeda.

Selanjutnya Drucker (1969) mengartikan pemasaran sebagai berikut: Marketing is not only much broader than selling, it is not specialized activity at all. Marketing encompasses the entire business. It is the whole business seen from the point of view of its final result, that is, from the customer point of view.

Dari pengertian di atas dapat dikatakan bahwa pemasaran merupakan tanggung jawab manajemen secara umum dan memprioritaskan pelanggan merupakan tangung jawab semua unsur yang ada dalam perusahaan. Banyak yang berpendapat bahwa pemasaran seharusnya memegang peranan penting dalam penetapan arah strategi suatu perusahaan. Hal ini cukup beralasan mengingat perencanaan strategis perusahaan merupakan suatu usaha untuk mempertahankan perusahaan tetap konsisten dengan lingkungan bisnisnya, dan pemasaran memiliki fungsi tradisional sebagai katalisator antara perusahaan dengan pelanggan, distributor dan pesaingnya. Kotler (1997) mengatakan bahwa: Pemasaran adalah proses sosial yang didalamnya individu dan kelompok mendapatkan apa yang mereka butuhkan dan inginkan dengan menciptakan, menawarkan dan secara bebas mempertukarkan produk yang bernilai dengan pihak lain. Stanton (1994) mempunyai pendapat, pemasaran adalah suatu sistem keseluruhan 
dari kegiatan-kegiatan bisnis yang ditujukan untuk merencanakan, menentukan harga, mempromosikan dan mendistribusikan barang dan jasa yang dapat memuaskan kebutuhan baik kepada pembeli yang ada maupun pembeli potensial. Dari definisi tersebut, dapat dikatakan bahwa kegiatan pemasaran adalah kegiatan-kegiatan yang saling berhubungan dengan orang lain sebagai suatu sistem. Selanjutnya Stanton beranggapan bahwa keberhasilan pelayanan dalam pemasaran menentukan keberhasilan perusahaan. Untuk itu kegiatan pemasaran harus dikoordinasikan dan dikelola dengan cara yang baik. Meskipun istilah pemasaran sukses dalam fenomena pemasaran sejak awal kemunculannya sangat beragam, namun dilihat dari berbagai definisi konsep pemasaran, bisa terlihat secara jelas ada sesuatu yang saling berhubungan antara produsen dan konsumen. Lebih jauh terdapat kecenderungan hubungan pertukaran yang merupakan hal penting dalam memahami dasar konsep pemasaran yang muaranya adalah untuk memenuhi human needs dan wants.

Merupakan perkerjaan yang tidak mudah bagi sebuah organisasi bisa memenuhi human needs dan wants. Untuk itu dalam implementasi konsep pemasaran dalam organisasi masih memerlukan perbaikan orientasi dan filosofi managerial. Lebih-lebih di kebanyakan organisasi menunjukan pertentangan filosofi dan ini memunculkan masalah dalam implementasi konsep. Filosofi pemasaran biasanya ditunjukan sebagai satu diantara sejumlah filosofi managerial yang secara terus menerus bersaing untuk kejelasannya di dalam organisasi.

Penulisan paper ini dilakukan dengan tujuan untuk mengungkap perkembangan konsep pemasaran,implementasi dan implikasinya. Penjelasan diawali dengan uraian tentang ruang lingkup pemasaran,bahasan kedua tentang konsep pemasaran dan perkembanganya, kemudian dilanjutkan dengan pembahasan tentang implementasi konsep pemasaran dan diakhiri dengan implikasi manajerialnya.

\section{RUANG LINGKUP PEMASARAN}

Keberadaan pemasaran tidak terlepas dari sebuah fenomena dan fakta yang berkaitan aktifitas pemasaran atau praktik pemasaran dan praktik pemasaran ini muncul sejak adanya kegiatan bisnis di tahun 1870 . Dimana fenomena pemasaran yang muncul pada saat itu sangat bervariasi (beranekaragam). Dengan keaneragaman ini mengakibatkan pandangan yang berbeda-beda bagi ahli pemasaran, tapi hasil dari keanekaragaman ini justru bisa memberikan kontribusi bagi perkembangan ilmu pemasaran.

Membahas tentang perkembangan konsep pemasaran, tentunya tidak bisa dilepaskan dengan ruang lingkup pemasaran yang luas, meliputi marketing mix, perilaku konsumen,komunikasi pemasaran dan masih banyak lagi yang menimbulkan keaneragaman fenomena. Berkaitan 
dengan hal itu maka agar lebih bisa dipahami, oleh Hunt (1991) dilakukan pengelompokan pada konferensi AMA tahun 1972. Hunt (1991) berusaha mengungkapkan hasil pengamatannya terkait dengan bagaimana mengklasifikasikan fenomena marketing.

Hunt (1991) mengatakan bahwa fenomena marketing dapat dikenali melalui dimensi positif - normative, micro - macro dan profit - non profit. Dalam perspektif positif yang menggambarkan, menjelaskan, memprediksi dan memahami aktifitas pemasaran dalam bentuk fenomenafenomena yang eksis. Sementara itu dalam perspektif normative, perspektif yang dipakai adalah memberikan gambaran tentang apa yang seharusnya dilakukan organisasi atau individu atau sistem pemasaran.

Sedangkan fenomena marketing bisa terjadi dalam organisasi atau institusi profit maupun non profit. Pada institusi profit adalah organisasi yang mempunyai tujuan untuk mendapat profit atau keuntungan. Sebaliknya organisai atau institusi non-profit adalah organisasi yang mempunyai tujuan tidak mencari profit. Fenomena marketing dalam cakupan mikro, aktifitasnya dijalankan oleh unit secara individual sedangkan pada cakupan makro lebih menunjuk pada tingkat kelompok Consumers, Social Responsibility (CSR).

Dengan berkembangnya pengertian pemasaran mulai dari lembaga bisnis sampai dengan non-bisnis dan juga perluasan dari pihak yang terlibat dalam pertukaran dalam pemasaran baik secara langsung maupun tidak langsung, maka cakupan bahasan pemasaran juga semakin luas. Secara umum cakupan bahasan dalam pemasaran meliputi antara lain (Hunt, 1976): consumer behavior, pricing, purchasing, sales management, product managemet, marekting communication, comparative marketing, social marketing, the efficiency/productivity of marketing system, the role of marketing in economic develiopment, packaging, channel of distribution, marketing research, societal issues in marketing, retailing, whloesaling, the social responsibility of marekting, international marketing, commodity marketing, and physical distribution.

Cakupan lain yang cukup menarik dilakukan oleh Kotler (dalam Hunt, 1991) dengan mengklasifikasikan pemasaran kedalam konsep mikro, makro, normatif, dan positif, sehingga diperluas menjadi 8 area yaitu profit sector, mikro, positf; non-profit sector, mikro, positif; profit sector, mikro, normatif; non-profit sector, mikro, normatif; profit sector, makro, positif; non-profit sector, makro, positif; profit sector, makro, normatif; dan nonprofit sector, makro, normatif. Terkait dengan mikro-makro/positif ini telah memunculkan berbagai macam konsep pemasaran. Konsep pemasaran yang demikian beragam ini kemudian menjadi semacam pedoman dalam praktik bisnis sehingga berakumulasi menjadi normative atau preskriptif (profit - non profit/mikro-makro/normative). Proses demikian terus berlanjut sehingga memunculkan semakin banyak fenomena pemasaran. Fenomena-fenomena yang ada dianalisis dan disajikan oleh para ahli 
pemasaran, selanjutnya digunakan sebagai acuan dalam memahami implementasi konsep pemasaran.

\section{PERKEMBANGAN KONSEP PEMASARAN}

Konsep pemasaran adalah sebuah falsafah bisnis yang menyatakan bahwa pemuas kebutuhan debitur merupakan syarat ekonomis dan sosial bagi kelangsungan hidup perusahaan (Henry Assael, 1990). Berdasarkan definisi tersebut, dapat diambil makna bahwa seluruh kegiatan dalam perusahaan harus ditujukan kepada pemuas kebutuhan konsumen, sehingga dapat diperoleh laba maksimum dalam jangka panjang, demi kelangsungan hidup perusahaan. Awal mula munculnya konsep pemasaran dikenalkan pada tahun 1950, bermula pada penilaian bahwa perusahaan terlalu berorientasi pada volume penjualan dan cenderung mengabaikan kepentingan konsumen. Karena pemasaran pada waktu itu, dianggap hanya mempunyai fungsi untuk menciptakan permintaan atas produk yang dihasilkan oleh perusahaan (Boarden, 1964). Konsep ini berpendapat bahwa faktor kunci untuk kemampuan memperoleh laba bukan hanya terletak pada jumlah penjualan yang dicapai, melainkan terletak pada kepuasan konsumen jangka panjang. Pada akhir tahun 1950-an dan awal tahun 1960-an, muncul perkembangan konsep pemasaran modern. Ada dua issu penting yang ada di dalamnya yang pertama marketing domain, area dimana konsep dipertimbangkan untuk diperluas dengan karakter yang jelas dari konsep itu sendiri dan yang ke dua adanya debat tentang domain yang tepat telah di awali oleh Kotler dan Levy (1969) yang menyatakan bahwa aktifitas marketing telah menembus penerapannya dalam bidang politik, universitas dan lembaga charitas seperti halnya pada perusahaan dengan orientasi profit.

Perkembangan teori pemasaran telah melampaui beberapa tahap. Secara historis perkembangan teori pemasaran dimulai dengan "The Marketing Revolution" yang di konsepkan Keith (1960) dengan dasar pada fenomena pemasaran pada saat itu, yaitu mengambil contoh kasus perusahaan Pillsbury sebagai satu-satunya perusahaan yang menjadi amatan Keith. Pada waktu yang hampir bersamaan teoritisi pemasaran disibukan oleh hasil pemikiran Levitt (1960) dengan "Marketing Myopia" yang mengungkap kegagalan perusahaan dalam merespon perubahan atas persyaratan customers.

Selama itu para praktisi pemasaran lebih memfokuskan pada produk yang dihasilkan dari pada pasar yang dilayani, yaitu terkait dengan tendensi untuk mendifinisikan tujuan perusahaan dan customers needs terlampau sempit . Drucker (1969) juga mengungkapkan bahwa tujuan perusahaan yang paling tepat adalah menciptakan kepuasan konsumen. Karena konsumen adalah merupakan pondasi bagi perusahaan untuk 
tetap mempertahankan kelangsungan hidupnya. Mendukung konsep yang diajukan Drucker, Levitt (1960) menyatakan bahwa kebutuhan pelanggan harus menjadi sentral dalam pendifinisian tujuan perusahaan, sementara pucuk pimpinan berkewajiban untuk menciptakan lingkungan, pandangan, sikap, dan aspirasi yang mendukung orientasi kepada pelanggan ini. Tahap perkembangan selanjutnya teori pemasaran memasuki masa yang disebut oleh Kotler (1972) dengan consciousness . Debat panjang tentang konsep marketing tidak dapat terelakkan, dalam pandangan Brown (1995) suatu masa dimana dalam teori pemasaran terjadi debat panjang itulah teori pemasaran memasuki periode modifikasi. Debat panjang ini kemudian mengharuskan para ahli pemasaran untuk mencermati kembali terhadap konsep dan filosofi pemasaran. Ketidakpuasan dan ketidaksempurnaan konsep dan teori pemasaran inilah yang kemudian memunculkan critical marketing theory yang awalnya dipicu adanya keraguan mereka. Tahap perkembangan berikutnya muncul upaya untuk memikirkankembalikonsep pemasaran yang memunculkan gagasan tentang paradigma baru dalam marketing yaitu apa yang disebut dengan post-modern marketing (Brown, 1993). Perspektif post-modernism dalam teori pemasaran bukan hanya menghindar dari evolusi konseptualisasi, tetapi juga mempertanyakan sejumlah generalisasi. Sikap penghindaran ini merupakan bentuk ketidak percayaan terhadap metanarative, sehingga memunculkan keraguan. Maka keraguan atas sejumlah teori pemasaran adalah kecenderungan reaksi dari post-modernist atas capaian dalam pengembangan teori-teori pemasaran.

Modern marketing muncul pada saat awal abad 20. Dalam perkembangan selanjutnya kemajuan pemasaran ditunjukkan empat tahap yang dicermintakan dengan pendekatan yang di adopsi : pendekatan komoditi, pendekatan institusi, pendekatan managerial dan pendekatan keperilakuan (Nataraajan, 1999). Abad 20 meski hanya beberapa tingkatan, momentum besar telah ditunjukan oleh marketing sebagai mesin ekonomi : large-scale retailing, chain-store, internet marketing, global market dan sebagainya. Bidang marketing sendiri telah berkembang secara spektakuler, yaitu dengan diperkenalkannya konsep empat P (Product, Price, Promotion dan Place) oleh McCarthy.

\section{IMPLEMENTASI KONSEP PEMASARAN}

Semenjak tahun 1960-an pendekatan profit/mikro-makro/positif maupun profit/makro-makro/normatif banyak menjadi focus bahasan untuk menjelaskan fenomena pemasaran yang terjadi di institusi bisnis maupun non-bisnis (Kotler 1972). Kajian-kajian terkait dengan mikromakro/positif ini telah memunculkan berbagai macam konsep pemasaran. Konsep pemasaran yang demikian beragam ini kemudian menjadi semacam pedoman dalam praktik bisnis sehingga berakumulasi menjadi normative atau preskriptif (profit - non profit/mikro-makro/normative). 
Proses demikian terus berlanjut sehingga memunculkan semakin banyak fenomena pemasaran. Fenomena-fenomena yang ada dianalisis dan disajikan oleh para ahli pemasaran, selanjutnya digunakan sebagai acuan dalam memahami implementasi konsep pemasaran antara tahun 1960 -1980-an.

Pada organisasi yang berorientasi pada sektor profit secara tegas menyatakan keberadaannya adalah untuk mencapai profit. Dan pada sektor profit ini banyak sekali dijumpai fenomena pemasaran. Sector profit meliputi makro-mikro/positif dan makro-mikro normative. Keith (1960) dalam tulisannya telah mengawali pembahasan pada sector profit $/ \mathrm{mikro} /$ positif. Keith mempercayai bahwa dalam setiap aktifitas pemasaran terpusat pada consumers. Dengan mengambil contoh kasus pada perusahaan Pillbury, Keith (1960) menggambarkan terjadinya revolusi pemasaran di perusahaan Pillsbury yang terbagi dalam empat masa, yaitu masa: orientasi produksi, orientasi penjualan, orientasi pemasaran, dan pengendalian pemasaran (marketing control). Dalam masa orientasi produksi, pusat perhatian perusahaan adalah terkait dengan (permasalahan fungsi) produksi, bukan pemasaran. Sehingga keputusan tentang produk baru adalah dari sudut pandang produksi, bukan sudut pandang pemasaran. Pada masa ini perusahaan dapat mendapatkan economics lot of scales dimana semakin banyak yang diproduksi dapat menurunkan biaya yang signifikan, demikian pula akhirnya keuntungan yang akan didapatkan. Hasilnya adalah pemasaran diabaikan (Levit, 1960)

Dalam masa orientasi penjualan, perusahaan sudah mulai memandang pentingnya konsumen sebagai kunci keberhasilan perusahaan, dan juga mulai timbul kesadaran tentang peran penting saluran distribusi sebagai kunci keberhasilan perusahaan. Permasalah inti yang dihadapi oleh perusahaan adalah adalah bagaimana produk yang dibuat perusahaan dapat dibeli konsumen, sehingga upaya yang perlu dilakukan adalah dengan melakukan kegiatan hard selling, bukan pemasaran. Pemasaran adalah lebih kompleks dari pada sekedar penjualan dan juga bukan hanya sekedar perbedaan bahasa. Penjualan lebih dahulu melihat kebutuhan dan kepentingan penjual, sementara pemasaran terlebih dahulu melihat kebutuhan konsumennya (Levit, 1960) Dalam masa orientasi pemasaran, konsumen sudah menempati posisi inti dimana kegiatan perusahaan bermula dan berakhir dari konsumen. Perusahaan tidak menghasilkan produk apa yang dapat diproduksi, tetapi produk apa yang dibutuhkan dan diinginkan konsumen itulah yang seharusnya dihasilkan perusahaan. Sehingga tujuan perusahaan tidak lagi menghasilkan produk, tetapi memuaskan kebutuhan dan keinginan konsumen baik yang riil maupun yang potensial.

Dalam masa pengendalian pemasaran (marketing control) sudah terjadi perubahan yang mendasar, dimana perusahaan tidak hanya 
menggunakan konsep pemasaran, tetapi menjadi 'marketing company' dengan suatu konsekuensi bahwa pemasaran harus dan selalu terkait dengan manajemen puncak (top management)

Fullerton (1988) menyatakan apa yang dilakukan Keith dengan mengangkat kasus Pillbury masih belum mampu menjelaskan kondisi eksternal social dan ekonomi yang terjadi pada saat itu. Fullerton juga mengatakan bahwa depresiasi yang besar yang terjadi pada 1930-an telah menjadikan situasi yang kurang baik bagi keberlanjutan dari era produksi. Sebab kondisi saat itu bisa menghambat para pelaku bisnis dalam menjual akibat terjadioverproduction. Keith dianggap telah mengabaikan fakta sejarah dimana dalam masa itu juga ada fenomena persaingan, overproduction dan demand tidak pasti. Maka jika pada masa itu tidak ada demand stimulation maka hal ini adalah salah, artinya upaya-upaya pemasaran yang dilakukan produsen telah diabaikan karena Keith dianggap telah mengabaikan pertumbuhan dan pasar baru.

Bagozzi(1975)dan Webster(1992)adalah penulis yang telah memaparkan fenomena yang eksis pada dimensi makro. Bagozzi (1975) melakukan kajian atas sejumlah dimensi paradigma pertukaran dengan penekanan pada apa yang menjadi pertimbangkan dalam pertukaran dengan fokus direct transfer dan media beserta makna dari exchange. Menurut Bagozzi secara umum pertukaran dibagai menjadi tiga tipe : (1) secara umum pertukaran terjadi antara dua fihak, (2) pertukaran yang terjadi paling tidak dilakukan oleh tiga fihak dalam satu situasi (3) pertukaran secara mutual relationship dalam sebuah system dengan pelaku paling tidak ada tiga pihak. Makna dari pertukaran itu sendiri menurut Bagozzi bukan hanya sekedar transfer produk untuk mendapatkan uang. Webster (1992), berpendapat bahwa marketing sebagai objek kajian sudah dimulai sejak tahun 1910 yang dilatar belakangi oleh sector pertanian. Pada saat itu marketing hanyalah sebagai proses social ekonomi dari aktifitas dan tanggung jawab manajerial.

Webster juga mengungkap bahwa tahun 1950 - 1960-an marketing manajemen mulai dipraktikan dan di maknai sebagai proses decision making dan problem solving dengan mengandalkan kerangka analisis ekonomi, psikologi, sosiologi, dan statistic. Dalam praktik secara luas diterima sebagai fungsi bisnis dan tumbuh melampaui pendekatan tradisonal sales manajemen dengan penekanan pada product planning and development, pricing, promotion, distribution. Pada saat itu riset pemasaran dianggap penting karena bisa membantu praktek manajemen.

Webster menungkapkan semakin besar organisasi, semakin banyak manager, analis dan planner yang tidak secara langsung terlibat dalam penciptaan penjualan product. Organisasi yang baru harus mampu merespon secara cepat dan fleksibel mengikuti perubahan teknologi, persaingan dan preferensi customers, dimana peran fungsional pemasaran bergeser dari lokal firm yang bergerak sepanjang kontimum, dari transaksi ke organisasi 
network. Peran baru marketing harus focus pada masyarakat, proses dan organisasi . Serta mensyaratkan mengenali operasi pada tiga jenjang yang berbeda perusahaan, unit bisnis dan fungsional. serta merefleksikan dalam tiga tingkatan strategy atau tiga dimentisi strategy (culture, strategy, tactic). Marketer harus bisa memanage tiga hubungan, yaitu customers, supplier dan re-seller karena ini berkaitan dengan customer needs.

Implementasi Profit/mikro-makro/Normatif, diwakili dengan tulisantulisan Ames (1970) dan Benneth and Cooper (1979), Sementara Ames (1970) menyatakatan: 'marketing in indutrial world is a total business philosophy aimed at improving profit performance by identifying the needs of each key customer group and then designing and producing a product/services package that enable the company to serve selected groups more effectively than does its competition'.

Dari definisi yang dikemukakan Ames (1970), terdapat empat dimensi pemasaran industri yaitu: meningkatkan kinerja keuntungan; penentuan kebutuhan konsumen; pemilihan pasar sasaran; dan, merancang dan menghasilkan alat pemuas kepada pasar sasaran tersebut,

Dalam kajiannya Ames (1970) marketing dalam dunia industry adalah total business philosophy tertuju pada peningkatan profit performance melalui identifikasi customers needs, dan kemudian mendesain dan memproduksi goods / service sehingga perusahaan mampu melayani kelompok customers terpilih dengan cara yang lebih efektif dibandingkan dengan competitor. Jadi esensi marketing lebih merupakan tanggung jawab manajemen secara umum.

Benneth and Cooper (1981) mengungkapkan profit/macro/normative dengan mengambil mencontoh terjadinya kalah persaingan dari industri automobile Amerika yang kalah bersaing dengan industri mobil dari Eropa dan Jepang. Benneth dan Cooper berpendapat bahwa kesuksesan produk diawali dari needs, dan needs tidak muncul ketika invention pada tahap product development. Pengembangan produk dilakukan oleh RD, sehingga marketing oriented juga ada pada RD. RD bertugas memberikan arahan untuk mengurangi resiko produk, inovasi, perubahan model dan inilah yang di sebut dengan strategi produk dalam konsep marketing.

Pada organisasi yang berorientasi pada sektor non profit keberadaannya adalah tidak semata-mata untuk memperoleh profit. Sektor non profit yang mulai tumbuh pada tahun 1960 ini juga banyak dijumpai fenomena pemasaran meskipun tidak sebanyak sector profit. Fenomena pemasaran yang terjadi pada sektor organisasi non profit pada dimensi makro dan mikro positiv terdapat dalam tulisan Kotler dan Levy (1969) dan Kotler (1972). Kajian Kotler dan Levy (1969) tentang interpreatsi marketing bagi organisasi nirlaba tidak jauh berbeda dengan organisasi profit. Dalam setiap organisasi product (physical, service, person, organization) dan idea consumers (suppliers, clients, direktur) dan marketing tools selalu menjadi 
titik sentral setiap pembahasan tentang marketing. Pemasaran organisasi selalu focus pada program yang telah didesain oleh pihak manajemen guna memebrikan kepuasan kepada stakeholder.

Menurut Kotler (1969) prinsip marketing manajemen dalam organisasi non-bisnis meliputi sembilan element : difinisi generic product, definisi target group, differentiated marketing, consumer behavior analysis, differential advantage, multiple marketing tools, integrated marketing planning, continous marketing feedback dan marketing audit. Marketing merupakan fungsi organisasi yang dapat menjaga hubungan dengan consumersnya, membaca kebutuhannya, mengembangkan produk untuk memenuhi kebutuhan dan membangun hubungan komunikasi untuk menyatakan tujuan-tujuan organisasi.

Fenomena terkait non-bisnis/makro-mikro/positif adalah apa yang diungkap oleh Kotler (1972). Dalam pandangan Kotler (1972), ada tiga tahapan kesadaran pemasaran (marketing consciousness) yang mempengaruhi sempit luasnya konsep pemasaran. Marketing consciousness one (tingkat kesadaran pertama ), adalah terkait dengan konsepsi bahwa pemasaran hanya terkait dengan lembaga bisnis sehingga pemasaran hanya terkait dengan penjual, pembeli, dan barang atau jasa, dimana konsep utamanya adalah terjadinya transaksi dengan inti konsep subjek bisnis dengan fokus transaksi pasar. Pokok perhatian kesadaran level pertama adalah seller, buyer dan economics product. Marketing consciousness two (tingkat kesadaran dua), menyatakan tidak mensyaratkan adanya pembayaran sebagai syarat terjadinya pemasaran dimana konsep pemasaran diperluas meliputi hubungan antara organisasi dengan anggotanya dengan inti konsep organization client transaction. Setiap organisasi menghadapi masalah terkait dengan produk yang dihasilkan dengan kelompok customernya. Untuk memecahkan masalah ini organisasi harus memahami ukuran (size) dan komposisi dari pasar, serta kebutuhan, sikap dan kebiasaan customer. Organisasi perusahaan harus mendesain produk untuk menarik target market. Pada kesadaran level dua ini marketing relevan pada semua situasi dimana marketer dapat mengidentifikasi organisasi, kelompok klien dan produk secara luas didefinisikan.

Pada fenomena non profit/makro-mikro/positif, Kotler (1972) menyatakan bahwa marketing relevan bagi semua organisasi, sepanjang organisasi itu menghasilkan produk dan mempunyai customers. Focus marketing telah mengalami pergeseran melewati commodity focus, institutional focus, functional focus, managerial focus dan social focus. Pergeseran focus terjadi akibat adanya kesadaran (consciousness) diantara pelakupelaku pemasaran. Pergeseran kesadaran dari satu tingkatan ke tingkatan yang lebih tinggi dari para pelaku akan menjelaskan dan membedakan batasan-batasan konsep marketing.

Houston (1986) telah melakukan suatu kajian tentang fenomena terkait dengan organisasi non-bisnis mikro-makro normative, ada dua 
hal yang dapat digunakan untuk menguji mana yang masuk konsep pemasaran dan mana yang tidak masuk dalam kosep pemasaran dua hal yang diuangkapkan Houston yaitu yang berkenaan dengan : (1) konsep produksi, sales dan marketing (2) statement tentang konsep pemasaran setelah dilakukan review pendapat tentang marketing concept beserta ideide yang melatar belakanginya.

Guna membedakan antara production concept, sales concept dan marketing concept, Houston menawarkan konsep alternative atas dasar perilaku seller - buyer dalam menemukan partner dalam pertukaran. Marketing concept ditandai oleh dimana kondisi buyer dan seller secara aktif mencari partner dalam pertukaran, sedangkan untuk Sales concept ditandai oleh kondisi seler yang secara aktif mencari partner dalam pertukaran. Sebaliknya untuk Production concept muncul dalam situasi seller hanya pasif menerima partner pertukaran.

\section{IMPLIKASI MANAJERIAL}

Berkaitan dengan munculnya modern marketing pada abad 20, menjadikan peranan penting pemasaran semakin berkembang. Perubahan lingkungan bisnis yang sangat cepat sebagai akibat dari pesatnya kemajuan dan penyebaran teknologi merupakan salah satu penyebab diterapkannya kembali konsep pemasaran dalam perusahaan untuk memperoleh keuntungan dari konsumen dan persaingan yang semakin tajam. Sehingga para pemasar selalu dituntut untuk lebih bisa berkreatif dan innovatif dalam menjalankan perannya .

Dengan adanya perkembangan teknologi telah mengubah dunia menjadi pasar tanpa batas, dengan perkembangan teknologi, khususnya kemajuan dalam teknologi informasi, membuat konsumen menjadi lebih mudah memperoleh informasi, tentang produk yang akan dikonsumsinya, dan memudahkan proses pemilihan produk (Denison and McDonald 1995). Dan konsep strategi korporasi tidak mampu lagi mengatasi perubahan lingkungan bisnis tersebut, karena perubahan lingkungan bisnis terlalu cepat sehingga mengarah pada penerapan kembali konsep pemasaran.

Pada dasarnya pelaku bisnis telah menyadari pentingnya kepuasaan pelanggan bagi kelangsungan usaha mereka. Hal ini ditunjukkan dengan semakin banyaknya perusahaan yang mengembangkan Program Pelayanan Konsumen dengan menggunakan teknologi sebagai alat bantunya. Upaya semua itu ditempuh guna menciptakan kepuasan pelanggan.

Pemasaran digital merupakan salah satu terobosan di dunia teknologi yang bisa membantu Dunia pemasaran akan memasuki era baru pemasaran. Di saat tradisional komunikasi pemasaran mengalami penurunan efektivitasnya sebuah cara baru di dunia pemasaran mengalami perkembangan yang siginifikan. Cara baru tersebut dikenal dengan 
pemasaran digital. Pemasaran digital yang menggabungkan faktor psikologis, humanis, antropologi, dan teknologi akan menjadi media baru dengan kapasitas besar, interaktif, dan multimedia. Hasilnya adalah era baru interaksi antara produsen, intermediari pasar, dan konsumen. Pemasaran yang berbasis pada digital akan memberikan gambaran, bagaimana proses tersebut sebagian atau seluruhnya dikombinasikan ke dalam bentuk kontak baru dengan konsumen melalui internet. Ini adalah sebuah terobosan baru untuk membangun hubungan dengan konsumen melalui media baru.

Perubahan teknologi akan berubah dari offline menjadi online, dari involuntary menjadi voluntary. Pelanggan akan secara sukarela mencari informasi tentang produk atau jasa yang dibutuhkan. Mereka bisa memproses informasi sesuai dengan ketertarikannya. Lebih interaktif karena konsumen memiliki keterlibatan tinggi terhadap produk atau jasa.

Melalui layanan tersebut terjadi pertukaran informasi baik yang berasal dari produsen maupun konsumen. Jadi dengan digitalisasi pemasaran, informasi akan lebih murah karena mudah didapatkan sehingga akan menurunkan biaya riset, akuisisi, dan retensi. Selain itu adanya respon yang cepat dari konsumen melalui layanan di internet, perusahaan bisa dengan cepat memahami keinginan dan kebutuhan konsumen. Ini berarti membantu percepatan inovasi dalam perusahaan. Keunggulan media baru dibandingkan tradisional akan memberikan peluang baru bagi perkembangan dunia pemasaran.

\section{PENUTUP}

Dengan terjadinya perubahan lingkungan dari setiap waktu dimana penerapan pemasaran dijalankan oleh organisasi, maka akan menghadapi suatu kesempatan dan kendala yang berbeda. Perbedaan tersebut menyebabkan terjadinya perubahan pemikiran pemasaran kearah yang lebih luas dan maju baik dari sisi pengertian, cakupan pemasaran maupun, konsep pemasarannya. Perkembangan pengertian pemasaran yang semula lebih menitik beratkan persoalan distribusi pisik dari perusahaan bisnis kemudian berkembang sampai pada kegiatan transaksi yang sekalipun tidak melibatkan mengeluarkan uang dan juga kegiatan pemasaran ini dapat dilakukan oleh kelembagaan diluar bisnis.

Sebagai konsekuensi dari perluasan pengertian tentang pemasaran, maka cakupan dari pemasaran juga semakin luas. Menjadi 8 area cakupan, yaitu profit sector, mikro, positf; non-profit sector, mikro, positif; profit sector, mikro, normatif; non-profit sector, mikro, normatif; profit sector, makro, positif ; non-profit sector, makro, positif; profit sector, makro, normatif; dan non-profit sector, makro, normatif. Kajian-kajian terkait dengan mikro-makro/positif ini telah memunculkan berbagai macam konsep pemasaran. Konsep pemasaran yang demikian beragam 
ini kemudian menjadi semacam pedoman dalam praktik bisnis sehingga berakumulasi menjadi normative atau preskriptif (profit - non profit/mikromakro/normative). Proses demikian terus berlanjut sehingga memunculkan semakin banyak fenomena pemasaran. Fenomena-fenomena yang ada dianalisis dan disajikan oleh para ahli pemasaran, selanjutnya digunakan sebagai acuan dalam memahami implementasi konsep pemasaran antara tahun 1960 -1980-an.

Perubahan teori telah terjadi dengan adanya alternative konsep tentang marketing diajukan oleh Fullerton (1988) dan Houston (1986). Dari segi konsep pemasaran, yang semula lebih mendudukkan perusahaan sebagai pihak pertama dan terakhir dari serangkaian kegiatan bisnis, berubah total menjadi konsumen sebagai awal dan akhir dari kegiatan perusahaan. Perkembangan peran marketing diungkapkan oleh Webster (1992) memberikan alternative terkini tentang konsep marketing yang berperan sebagai organizational network. Konsekuensi logisnya semua kegiatan perusahaan harus diarahkan ke konsumen, mengingat kondisi persaingan sudah semakin meningkat, akan tetapi dalam melakukan kegiatannya, perusahaan harus dituntut bisa melaksanakannya lebih baik dari pesaingnya agar pada akhirnya bisa memberikan kepuasan konsumen dan ini merupakan tujuan perusahaan.

Agar pemuasan konsumen dapat dilakukan secara terpadu, maka perusahaan sebaiknya menggunakan pemasaran sebagai konsep bisnis strategic yang memberikan kepuasan yang berkelanjutan, bukan sesaat, tidak hanya bagi investor/pemilik dan konsumen tetapi juga memberikan kepuasan yang berkelanjutan juga bagi para karyawannya. Dalam konsep ini perusahaan berusaha untuk memuaskan semua stakeholder nya.

Tapi realita menunjukkan bahwa meskipun banyak pelaku bisnis yang sadar akan pentingnya kepuasan pelanggan namun masih sedikit dari mereka yang menjalankan program pelayanan pelanggan secara baik dan benar. Program memuaskan pelanggan masih sebatas slogan dan bersifat seremonial. Mereka lebih cenderung berburu pelanggan baru dan mengabaikan pelanggan yang sudah ada. Fenomena ini dapat dilihat pada pengalokasian biaya pemasaran yang sebagian besar ditujukan untuk promosi dan hanya sebagian kecil yang ditujukan untuk mempertahankan pelanggan 


\section{Daftar Pustaka}

Ames, C., (1970) “Trappings vs Substance in 'industrial Marketing”, Harvard Business Review, July-Aug., pp.93-102.

Assael, H. (1990),"Assael marketing : Principles \& Strategy", Publisher: Thomson Learning

Bagozzi, R., (1975) "Marketing as Exchange", Journal of Marketing, 39, 4, pp.32-39.

Bennett, R. C. and R. G. Cooper (1979), "Beyond the Marketing Concept." Business Horizons (June): 76-83.

Bennett, R. C. and R. G. Cooper (1981), “The Misuse of Marketing: An American Tragedy." Business Horizons (Nov-Dec): 51-61.

Brown, S., (1993), "Postmodern Marketing?", European Journal of Marketing, 27 (4): $1-34$

Brown, Stephen (1995), "Life Begins at 40? Further thoughts on marketing's "mid-life crisis", Marketing Intelligence $\mathcal{E}$ Planning, 13 (1).ABI.Inform global.pg 4

Boarden,H.N,(1964),"The Concept of the Marketing Mix" Journal of Advertising Research

Drucker,P.F.(1969),"The Practice of Management", New York: Harper E Row

Denison,T. and M.Mc Donald(1995)."The Role of Marketing Past,Present and Future",Journal of Marketing Practice :Applied Marketing Science

Fullerton (1988),"How Modern is modern marketing ?,Marketing's evolution and the myth of the production era", Journal of Marketing. Vol.52.pp.108-25

Houston, F., (1986) “The Marketing Concept: What it is and what it is not", Journal of Marketing, 50, 2, pp.81-87

Hunt, S.D. (1991) Modern Marketing Theory. Critical Issues in the Philosophy of Marketing Science, South Western Publishing Company. Chapter 1.

Keith, R. J. (1960), “The Marketing Revolution." Journal of Marketing 24 (January): 35 - 38.

Kotler, P., \& Levy, S.J. (1969), 'Broadening the Concept of Marketing', Journal of Marketing, January, pp.10-15.

Kotler, P. (1972), "A Generic concept of Marketing." Journal of Marketing 36 (April): $46-54$ 
Kotler, P.(1997)," Marketing Management: Analysis, Planning, and Control". 9th Ed. London: Prentice-Hall, International.Inc

Levitt, T.(1960), 'Marketing Myopia', Harvard Business Review, Jul-Aug, pp.45-63.

Nataraajan, R. and Bagozzi, R. P. (1999), “The Year 2000: Looking Back”, Psychology \& Marketing 16 (8)

Stanton, W.J.(1994), Fundamentals of Marketing, 10th Ed. Tokyo: Kogakusha, McGraw-Hill Book Company

Webster (1992), "The changing role of marketing in the corporation", Journal of marketing.Vol.56.Oktober.pp.1-17 